\title{
Transition-Metal Catalyzed Multi-Component Carbocyclization and Related Reactions of Bifunctional Molecules
}

\author{
Kenji Itoh,* Isamu Matsuda, and Yoshihiko Yamamoto \\ Department of Molecular Design and Engineering, Graduate School of Engineering, \\ Nagoya University,
}

\begin{abstract}
The selective $[2+2+2]$ cycloaddition of 1,6-diynes takes place to give polycyclic 1,3-cyclohexadienes or arenes using ruthenium or palladium complex catalysts. The rhodium carbonyl cluster is an efficient catalyst for the three-component coupling between carbon monoxide, hydrosilanes, and 1,6-diynes or 1,6-enynes. Organotitanium(III) complexes are excellent reagents for the intramolecular carbon-carbon bond formation between the nitrile and carbonyl groups as well as the intramolecular pinacol coupling of dials.
\end{abstract}

\section{Introduction}

Since the pioneering discovery of the nickel-catalyzed cyclooligomerization of acetylene by Reppe and his co-workers, a tremendous number of catalytic processes have been developed. Now a variety of linear and cyclic hydrocarbons can be prepared in short steps from simple unsaturated hydrocarbons using various transition-metal catalyst (ref. 1). The commercial production of eight- and twelve-membered carbocyclic compounds from butadiene is a representative example of these reactions. Most of these catalytic cyclooligomerizations were claimed to proceed by way of a carbon-carbon bond formation between two coordinated hydrocarbons to give higher-valent metallacycle intermediates (oxidative cyclization), which induce the insertion of the third molecule into one of their metal-carbon bonds to an enlarged metallacycle intermediate, from which the intramolecular $\mathrm{C}-\mathrm{C}$ bond formation takes place to produce coupling products. It is, however, generally difficult to couple different kinds of hydrocarbons (in a cross-coupling mode) with high selectivity. In addition, the judicious control of the regio- and stereoselectivities is also a problem. In order to circumvent these difficulties, several approaches make use of bifunctional substrates, such as dienes, enynes, diynes, etc., as one of the coupling components. The Pauson-Khand reaction is a representative and pioneering example of such approaches. In the first part of this article, we report our recent approach using ruthenium and palladium-catalyzed cyclocotrimerizations and rhodium-catalyzed silylative and carbonylative cyclization of 1,6-diynes, 1,6-enynes, and 1,6-dienes. Secondly, Ti(III)-mediated radical cyclization of ketonitriles and a pinacol type stereoselective cyclization of dials are discussed.

\section{Ruthenium(II)-Catalyzed $[2+2+2]$ Cycloaddition of 1,6-Diyne with Alkenes and Its Extension to Tandem Cycloaddition}

The oxidative cyclization of two alkyne molecules and a variety of low-valent transition-metal complexes has been reported to form metallacyclopentadiene complexes which are important intermediates for the catalytic cyclotrimerization of alkynes and the cyclocotrimerization of two alkyne molecules with a wide range of polar or nonpolar unsaturated bonds (ref. 2). When 1,6-diynes are 
utilized as the starting materials for ruthenium-catalyzed cyclocotrimerization, ruthenabicyclo[3.3.0]octadiene intermediates are expected to be formed during the first step of the catalytic cycle. In fact, on treatment of dimethyl dipropargylmalonate (1 a) with an excess amount of 2,5-dihydrofuran (2a) in the presence of catalytic amounts of $\mathrm{Ru}(\mathrm{C} 5 \mathrm{Me} 5)(1,5$-cyclooctadiene $) \mathrm{Cl}$, $\mathrm{Cp} * \mathrm{Ru}(\mathrm{cod}) \mathrm{Cl}$, the corresponding 1,3-cyclohexadiene derivative (3aa), a [2+2 +2] cycloadduct, was selectively obtained at $40^{\circ} \mathrm{C}$ (eq. 1). Equation 5 summarizes these results with several 1,6-heptadiyne derivatives (1) which were reacted with 2,5-dihydrofuran as a reference cyclic alkene (2) (ref. 3). It is important that the catalytic cycloaddition takes place in the case of cyclic or linear alkenes possessing a heteroatom or a hetero functional group at the allylic position (eqs. 2-4). The 1,3-cyclohexadiene products (3) are useful for the diene component of the Diels-Alder reactions. For instance, 3aa furnished the Diels-Alder adduct $\mathbf{4 a}$ with maleic anhydride, and its structure was unequivocally determined by an X-ray analysis indicative of its exo, exo-stereochemistry (eq. 6; ref. 4). Similarly, the reaction between 3aa and $N$-phenylmaleimide affords $4 \mathbf{b}$ (eq. 6).

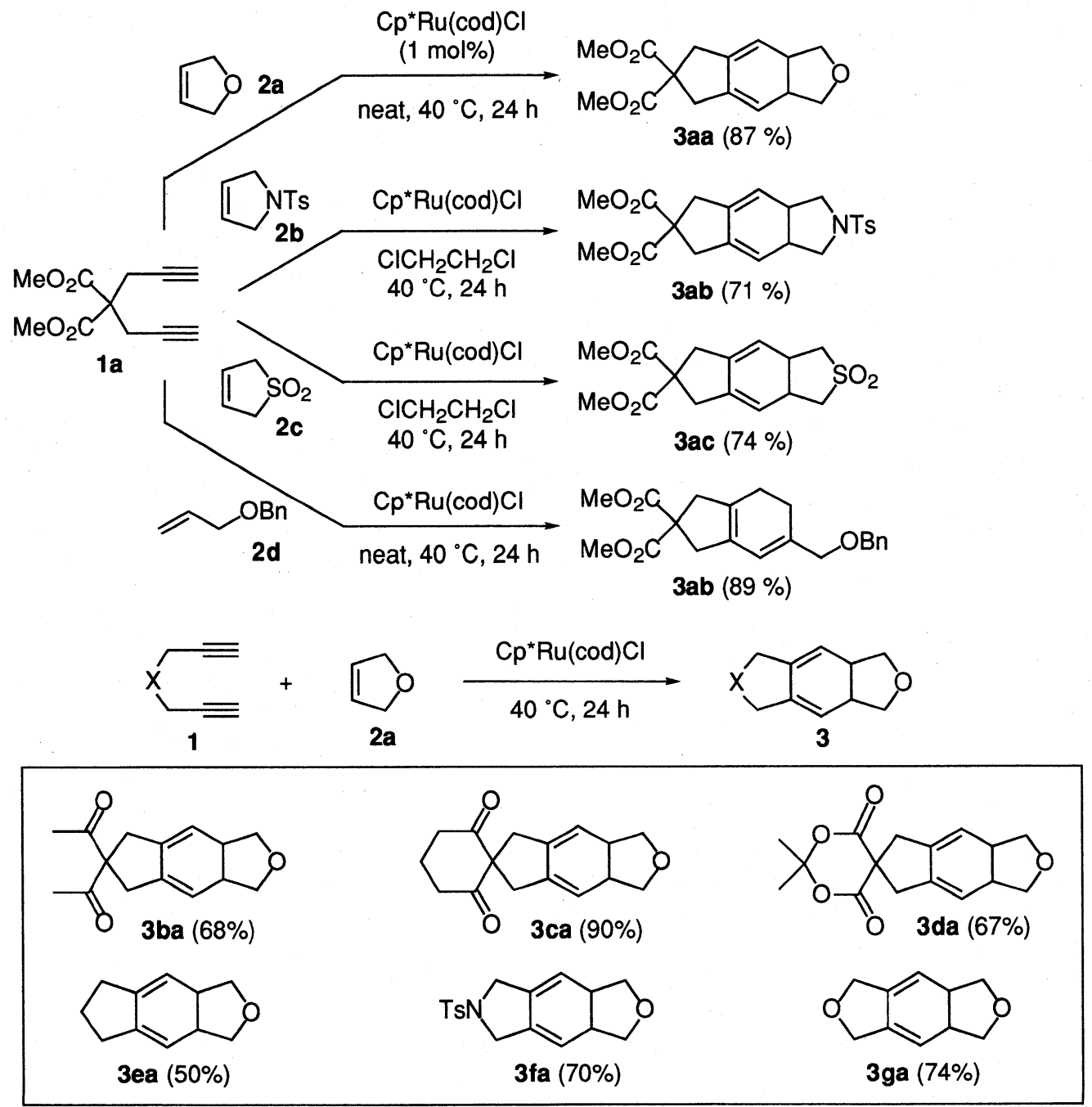




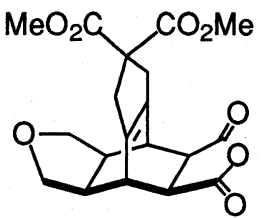

$4 a(69 \%)$

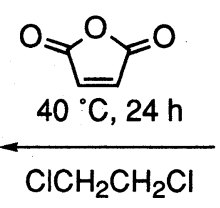

$\mathrm{ClCH}_{2} \mathrm{CH}_{2} \mathrm{Cl}$<smiles>COC(=O)C1(C(=O)OC)CC2=CC3COCC3C=C2C1</smiles>

3aa

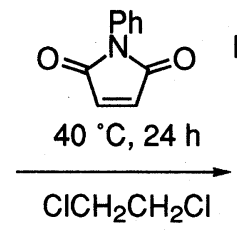

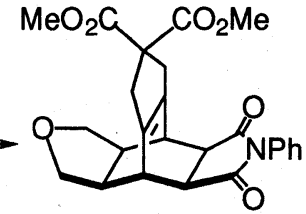

$4 b(75 \%)$

When an excess of $N$-phenylmaleimide was reacted with $1 \mathbf{a}$ in the presence of a catalytic amount of $\mathrm{Cp} * \mathrm{Ru}(\mathrm{cod}) \mathrm{Cl}$, the catalytic $[2+2+2]$ cycloaddition and the subsequent $[4+2]$ cycloaddition took place in one operation giving the highly symmetric tandem adduct $4 \mathrm{c}$ in high yield (eq. 7).

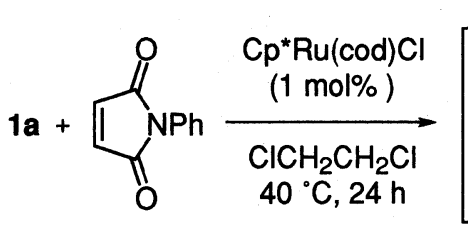

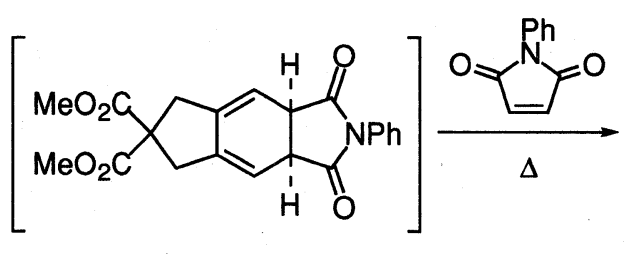
$2 e$ (10 eq.)

When bicyclic alkenes (5), such as norbornene derivatives (5a-c) or bicyclo[3.2.1]octenones (5d and 5e), were used as the alkene components, the yields and selectivity of the expected [2+2 +2$]$ cycloadducts were lower than those with allylic ethers (2a and $\mathbf{2 d}$ ) under analogous conditions. Substantial amounts of a different kind of tandem 1:2 adducts (6) were isolated (ref. 5). The yields of 6 significantly increased when $\mathrm{Ru}$ (Indenyl)Cl(PPh3)2 was employed as the catalyst (Table 1). For instance, the reaction of $\mathbf{1 a}$ with 2,4-dimethylbicyclo[3.2.1]octen-3-one $\mathbf{5 d}$ in the presence of the indenylruthenium catalyst gave the unexpected tandem adduct $\mathbf{6 a d}$, composed of one molecule of $1 \mathrm{a}$ and two molecules of 5d. The X-ray structure determination of 6 ad indicated a very unique and unexpected structure with high symmetry involving a 1,2-dicyclopropylcyclopentene structure (eq. 8). This result strongly supports the view that the metallacyclopentadiene intermediate can behave as a biscarbenoid equivalent, expected from the 1,3,5-metalacyclopentatriene resonance form (eq. 9). In this context, Taube et al. recently claimed that a tetramethylosmacyclopentadiene ethylenediamine complex showed a well-defined structure anticipated from the predominant resonance contribution of a 1,3,5-metallacyclopentatriene structure (ref. 6).

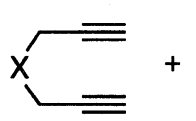

1

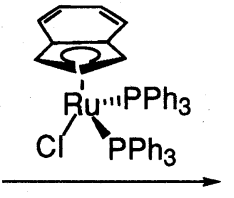

5

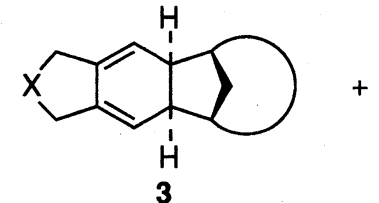

3

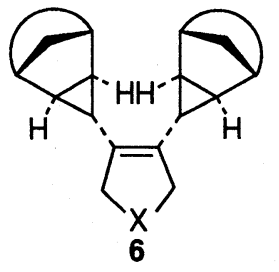


Table 1. Ruthenium-catalyzed tandem cycloadditions between 1,6-diyne with bicyclo[n.2.1]alkenes.

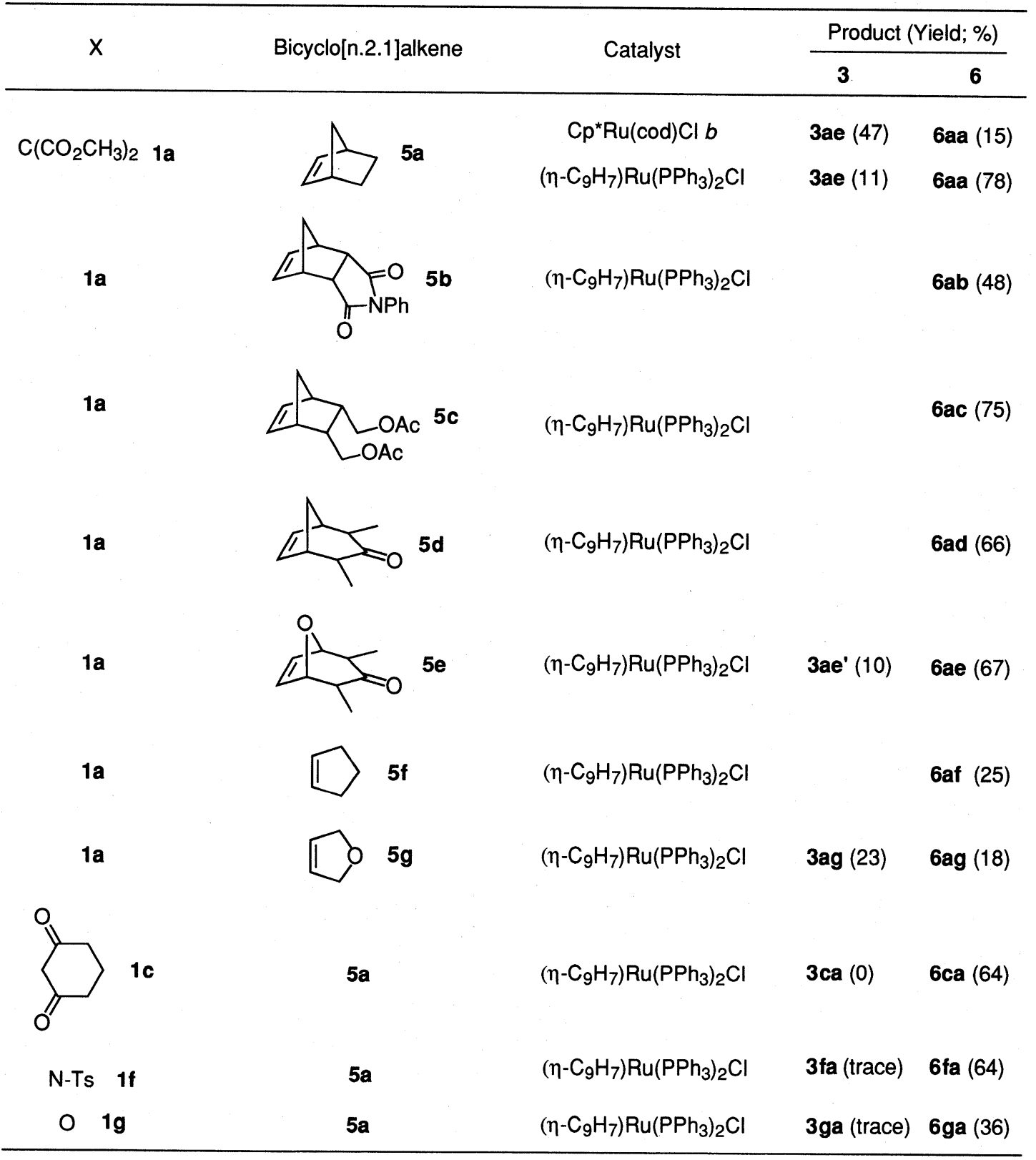

Catalytic cyclization of 1,6 - or 1,7-dienes $(\mathbf{7} \mathbf{a}-\mathbf{f})$ is also possible using much simpler ruthenium(II) chloride complexes. Selective cyclization of 1,6-heptadiene (7) and 1,7-octadiene (7g) derivatives readily occurred to selectively generate the corresponding exo-methylenecyclopentane (8ag) by means of several Ru(II) complexes in alcoholic solvents (eqs. 10 and 11). In particular, the sparingly soluble and air-stable oligomeric chloride complex, $[\mathrm{RuCl} 2(\mathrm{cod})] \mathrm{n}$ was found to be extremely 
effective even under heterogeneous conditions (ref. 7). The double bond isomerization of both starting materials and products never occurred. All manipulations can be done in air. A representative $\operatorname{Ru}(0)$ complex, $\mathrm{Ru}(\operatorname{cod})(\cot )$, was also effective for the cyclization of 7a to $8 \mathrm{a}$ in 1,2-dichloroethane.
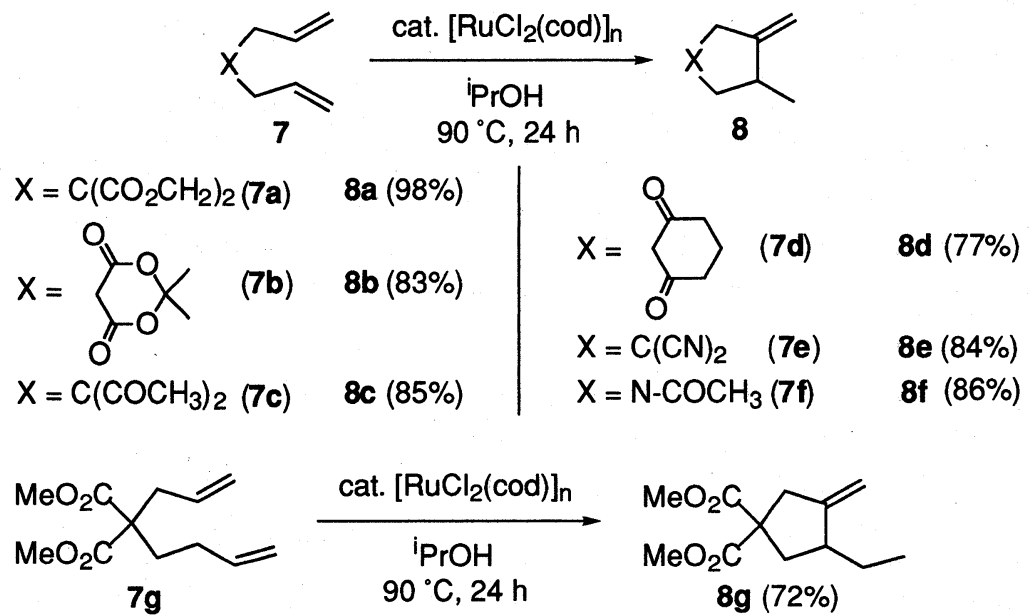

The related catalytic formations of exo-methylenecyclopentane from 1,6-dienes have already been reported with several transition metal complexes of $\mathrm{Ni}, \mathrm{Rh}, \mathrm{Pd}$, etc., and some lanthanoid complexes (ref. 8).

\section{Silylative Cyclization of 1,6-Diynes and 1,6-Enynes}

A decade ago, one of the authors (I.M) discovered the silylformylation of alkynes (eq. 12). This is the three-component coupling between an alkyne, hydrosilane, and carbon monoxide, and it proceeds with a high degree of regio- and stereoselectivities (ref. 9). Under low pressure carbon monoxide or with a less reactive hydrosilane (eq. 13), the products became a mixture of the expected silylformylation product (9a) and 2-organosilycyclopentenones (10a and 10a'), of which the formation was explained in terms of the double insertion of two alkyne molecules into the $\mathrm{Si}$ - $\mathrm{Rh}$ bond of the hydridosilylrhodium(III) intermediate prior to the carbonyl insertion followed by the intramolecular insertion of an acyl-rhodium species (ref. $9 \mathrm{~g}$ ). On the basis of this mechanistic approach, two alkyne components were combined. Thus, a domino cyclization from 1,6-diynes (1), hydrosilane, and carbon monoxide was realized in the presence of $\mathrm{Rh} 4(\mathrm{CO}) 12$ or mononuclear rhodium carbonyl complexes as catalysts (eq. 14; ref. 10). The three-component coupling provides silyl substituted bicyclo[3.3.0]octenones (1 2) in a single operation.

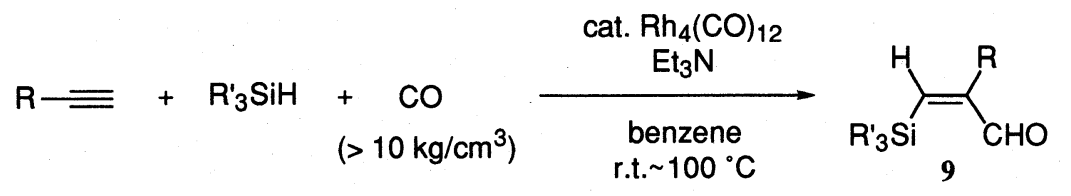



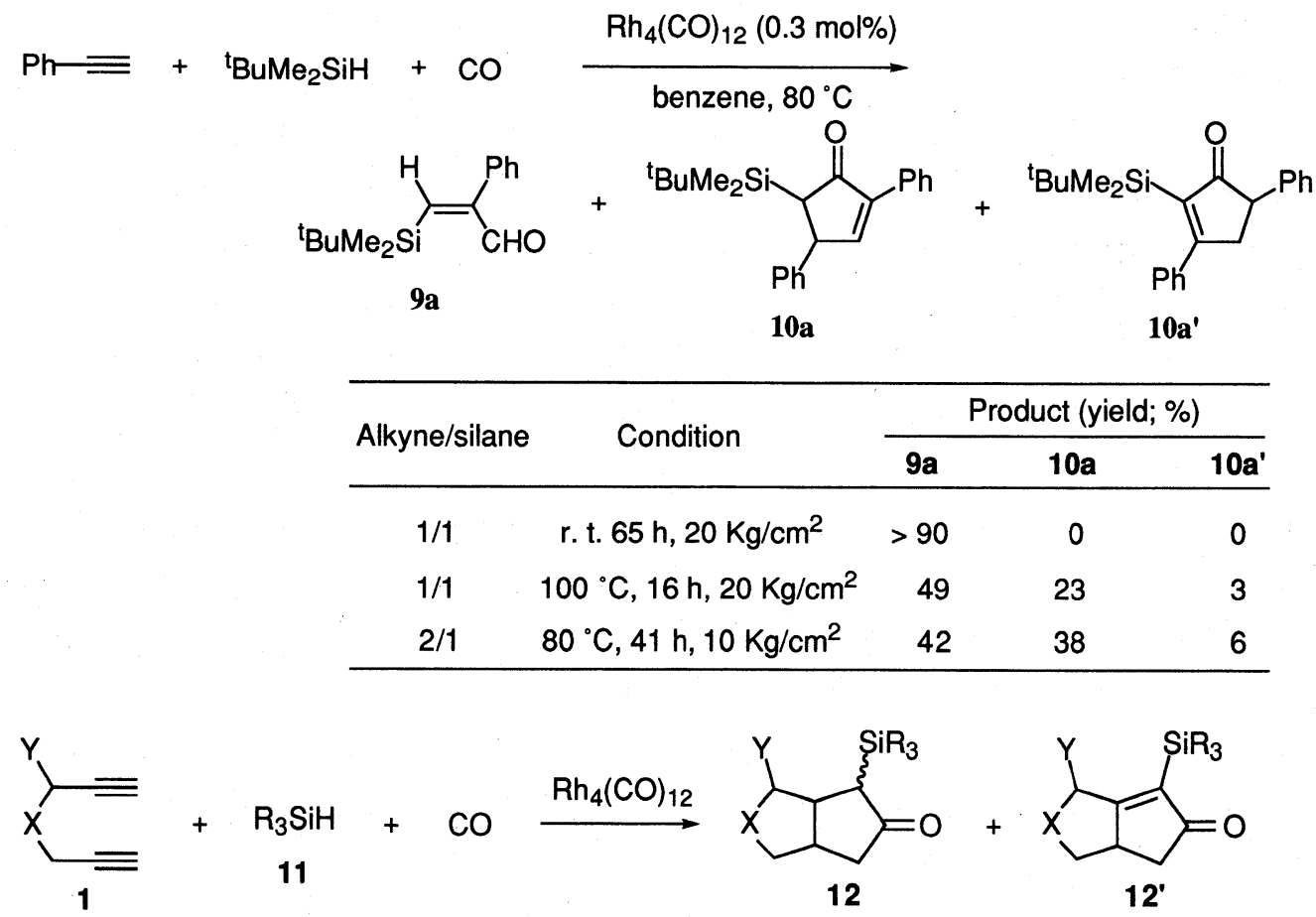

$$
X=\mathrm{CH}_{2}, \mathrm{C}\left(\mathrm{CH}_{3}\right)_{2}, \mathrm{C}\left(\mathrm{CO}_{2} \mathrm{R}^{\prime}\right)_{2}, \mathrm{NR}^{\prime}, \mathrm{O}, \text { etc; } \mathrm{Y}=\mathrm{H}, \mathrm{OSiR}_{3}^{\prime}
$$

On the other hand, the cyclization from 1,6-enynes (13), which are typical substrates in Pauson-Khand reactions, which have now become a catalytic process (refs. 11 and 12), resulted in the formation of [2-exo-(silylmethylene)cyclopentyl]acetaldehydes (14) under similar conditions (eq. 15 and Table 2; ref. 13).

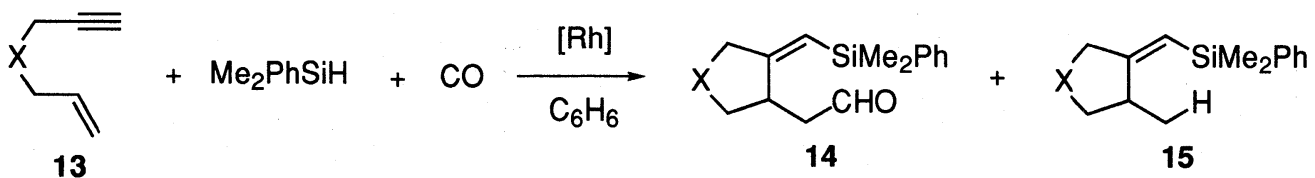

Another extension of the rhodium-catalyzed silylformylation is the hydrosilylation of $1,6-$ diynes forming five-membered ring products, bis[exo-(methylene)]cyclopentanes (15). When a 1,6diyne, 1a, was treated with a hydrosilane (11a) in the presence of a preformed silylrhodium-hydride complex, $\mathrm{Rh}(\mathrm{H})\left(\mathrm{SiR}_{3}\right) \mathrm{Cl}(\mathrm{PPh} 3)_{2}$ prepared from $\mathrm{RhCl}(\mathrm{PPh} 3)_{3}$ and the corresponding 11, a silylative cyclization of the 1,6-diyne proceeded to give 15 as predominant products (eq. 16; ref. 14). If $\mathrm{RhCl}(\mathrm{PPh} 3)_{3}$ is used directly as a catalyst, undesirable self-dimerization or trimerization of the $1,6-$ diynes took place. This finding suggests that the double insertion of alkyne into the $\mathrm{Si}-\mathrm{Rh}-\mathrm{H}$ species plays an important role in the catalytic silylative cyclization. 
Table 2. Rhodium-catalyzed domino silylative and carbonylative cyclization of 1,6-enynes.

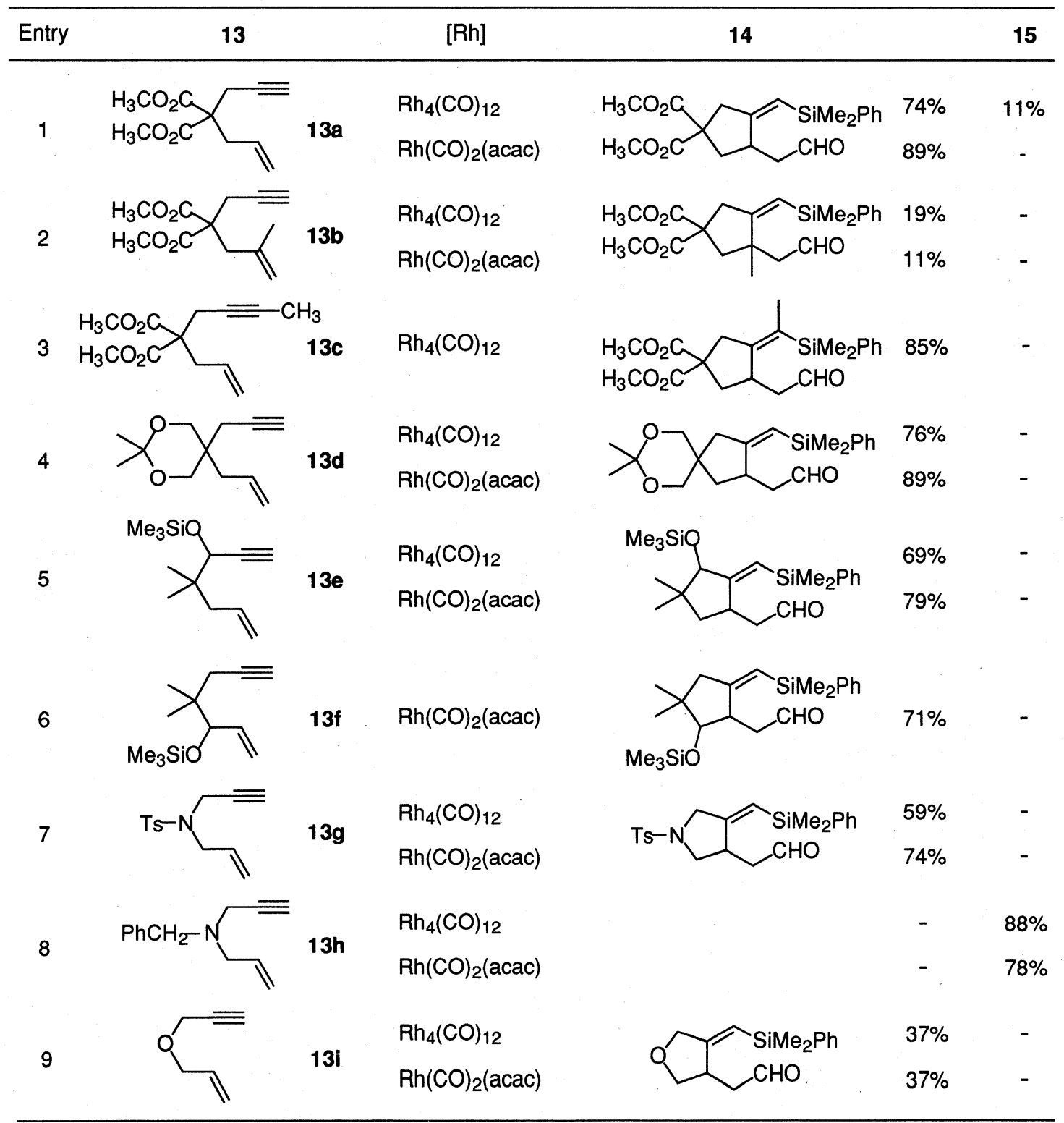

Conditions: $\mathrm{Rh}_{4}(\mathrm{CO})_{12}$ or $\mathrm{Rh}(\mathrm{CO})_{2}$ (acac) $(0.5 \mathrm{~mol} \%, 0.005 \mathrm{mmol})$, Enyne (1 mmol), Me ${ }_{2} \mathrm{PhSiH}$ (1.2 eq., 1.2 $\mathrm{mmol}), \mathrm{CO}\left(20 \mathrm{Kg} / \mathrm{cm}^{2}\right), \mathrm{C}_{6} \mathrm{H}_{6}(10 \mathrm{ml}), 90^{\circ} \mathrm{C}, 14 \mathrm{~h}$ 

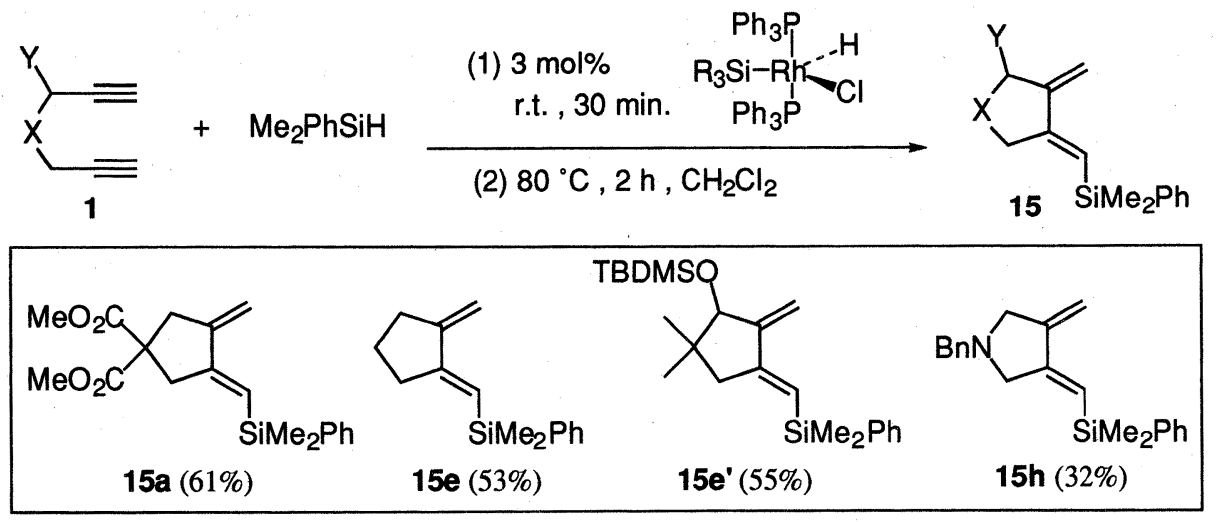

The rhodium-catalyzed silylformylation of alkynes was modified as a silylative carbamoylation of alkynes, alkynols, or alkynylamines (16) to the related (Z)-acrylic acid amides, (Z)silylmethylenelactones or (Z)-silylmethylenelactams (17) (ref.9d, 9e, and 15). Representative examples are shown in eqs. 17 and 18 for the construction of the 4-8-membered lactams.

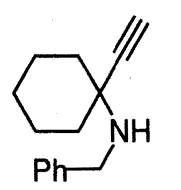

$16 a$

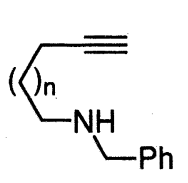

16

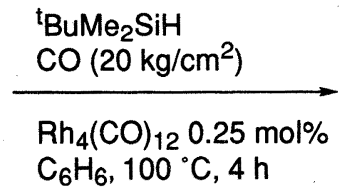

$\mathrm{C}_{6} \mathrm{H}_{6}, 100^{\circ} \mathrm{C}, 4 \mathrm{~h}$

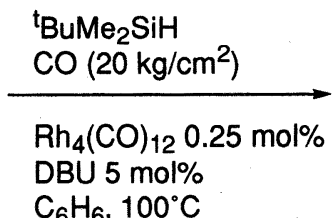

$\mathrm{C}_{6} \mathrm{H}_{6}, 100^{\circ} \mathrm{C}$

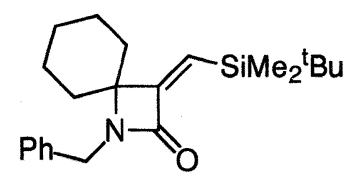

$17 a(98 \%)$

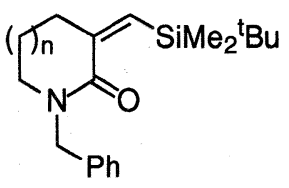

17

$n=0 ; 93 \%(2 h), n=1 ; 68 \%(2 h), n=2 ; 79 \%(16 h), n=3 ; 39 \%(14 h)$

\section{Pd(0) Catalyzed Cross Coupling of Diyndioates with Alkynes}

Previously, one of authors (K. I.) reported the palladium-catalyzed cyclocotrimerization of two dimethyl acetylenedicarboxylate (DMAD) molecules with several alkenes via the corresponding palladacyclopentadiene intermediate (ref. 16). Due to the strong basicity of the $\operatorname{Pd}(0)$ catalyst, the alkyne components available for the cyclocotrimerization were practically limited to the highly electrondeficient DMAD, which also did not cause any regiochemical complexity during the metallacycle formation. Unsymmetrical alkynes, for instance, methyl propiolate induced a non-regioselective cotrimerization to give both 1,2,4- and 1,3,5-tris(methoxycarbonyl)benzenes in favor of the 1,2,4substituted isomer. Furthermore, a cross-coupling between two different kinds of alkynes is extremely difficult to attain a desirable composition with high regioselectivity because electron demands of the two analogous substrates with the identical alkyne groups are too close to discriminate between them.

With these problems and experiences in mind, we designed an alkyne substrate as 1,6-diyne derivative which involves methoxycarbonyl groups at both ends in order to provide sufficient 
electrophilicity to the two alkyne components. Several 5-substituted dimethyl 2,7-nonadiyndioates (18) were thus reacted with $\mathrm{DMAD}$, as an acceptor alkyne, using a $\mathrm{Pd} 2(\mathrm{dba}) 3 / \mathrm{Ph} 3 \mathrm{P}$ catalyst (ref. 17). The presence of a heteroatom or a quaternary carbon, involving heteroatom substituents at the 5position, in particular dipropargylethers (18a) showed extremely high efficiency to give 19a via the selective $[2+2+2]$ cross-trimerization of the dynes with DMAD (eq. 19).

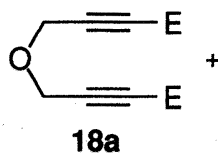<smiles>[CH-]C#C[CH-]</smiles>

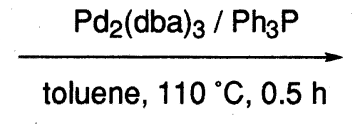
$\mathrm{E}=\mathrm{CO}_{2} \mathrm{Me}$<smiles>Fc1c(F)c(F)c2c(c1F)COC2</smiles>

$19 \mathrm{a}(78 \%)$<smiles>Fc1c(F)c(F)c(F)c(F)c1F</smiles>

This transformation can be successfully extended to a domino process. Dimethyl 5,10 dioxa-2,7,12-tetradecatriynedioate (21) selectively furnished the intramolecular $[2+2+2]$ cycloadduct (2 2) in $85 \%$ yield as a single product (eq. 20).

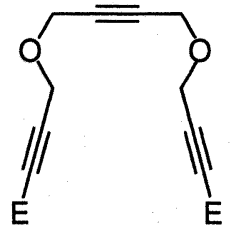

21

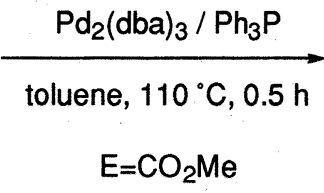

$\mathrm{E}=\mathrm{CO}_{2} \mathrm{Me}$

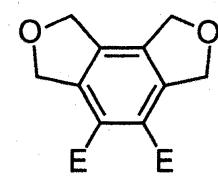

$22(85 \%)$

\section{Organotitanium(III) Induced Radical Cyclization of Ketonitrile and Related Polar Di-oxofunctional Substrates}

The transition metal-mediated cyclization of bifunctional molecules is not limited to carboncarbon multiple bonds. The oxophilic and paramagnetic organotitanium(III) reagent, $\mathrm{Cp} 2 \mathrm{TiPh}$, generated in situ from a sequence of reactions of $\mathrm{Cp}_{2} \mathrm{TiCl}_{2}$ with ${ }^{\mathrm{i}} \mathrm{PrMgBr}$ followed by $\mathrm{PhMgBr}$, generates ketyl radicals which may intramolecularly add to a coordinated cyano group of ketonitriles (23) to give the corresponding 2-hydroxyalkanones (24) after hydrolysis (refs. 18 and 19). The two Ti(III) species separately coordinate to both carbonyl oxygen and the cyano group in 23 . A semiempirical calculation suggested that the former interaction produces carbon-centered ketyl radicals, whereas the latter coordination is indicative of the spin density being located on the titanium atom (ref. 19). Consequently, this ring closure can be regarded as a kind of radical cyclization of the ketyl radical to the coordinated polar multiple bond (eqs. 21 and 22). It is important that the titanium(III)induced ketyl radical cannot add to the C-C double bonds as claimed in the case of the SmI2-mediated cyclization (ref. 20). A tandem approach of the ketonitrile cyclization also proceeds with 25 to give a triquinane skeleton (26) (eq. 23). 
<smiles>N#CCCC1CCCC1=O</smiles>

23
$\mathrm{Cp}_{2}$ TiPh (22)

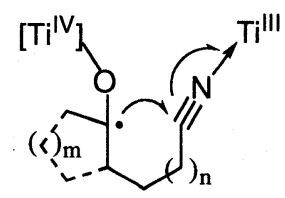

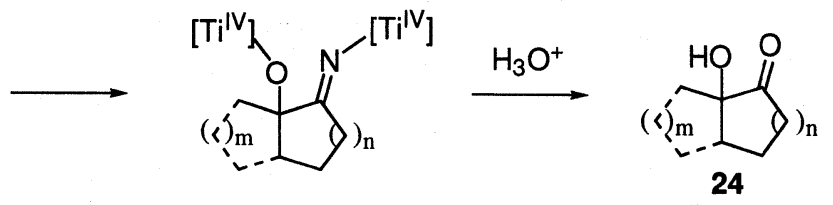

$\mathrm{rt}, 2 \mathrm{~h}$

2. aq. $\mathrm{HCl}$<smiles>N#CCCC1CCCC1=O</smiles>

23a, $n=1, m=1$

23b, $n=2, m=1$

23c, $n=2, m=2$

\section{2. aq. $\mathrm{HCl}$ \\ 1. $C p_{2} T i P h$ \\ $\mathrm{rt}, 2 \mathrm{~h}$}<smiles>O=C1CCC[C@H]2CCCC[C@]12O</smiles>

24c (69\%; trans) 24a, $n=1(77 \%)$

$24 b, n=2(70 \%)$

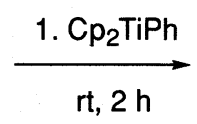

2. aq. $\mathrm{HCl}$

25<smiles>O=C1CC[C@]23CCC(=O)[C@@]2(O)c2ccccc2[C@@]13O</smiles>

26 (75\%)

Such titanoxyketyl radical cyclization can be extended to the catalytic coupling between the two carbonyl groups (eq. 24). Thus, pinacol coupling of $\alpha, \omega$-dials (27) successfully proceeded under catalytic conditions $\left(\mathrm{Cp}_{2} \mathrm{TiPh} / \mathrm{Zn} / \mathrm{Me} 3 \mathrm{SiCl}\right)$ as shown in eq. 25 and Table 3 . The important feature of this coupling is the stereochemical outcome of the cyclic 1,2-diols (28) which showed the predominant trans configuration. The enhanced steric requirement of the two $\mathrm{Cp} 2 \mathrm{TiPh}$ moieties forced the two bulky titanoxy(IV) ketyl radicals to locate apart from each other (ref. 21).

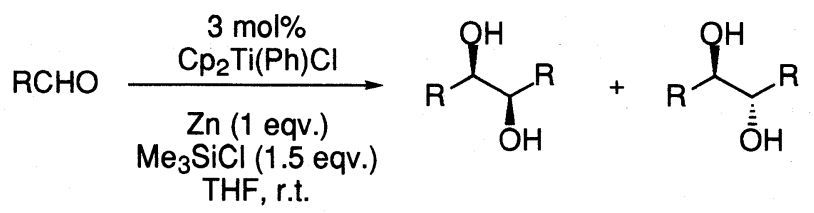

$\mathrm{R}=\mathrm{Ph}, 0.12 \mathrm{M}, 70 \mathrm{~min}, 88 \%$ (threo : erythro $=71: 29$ )

$\mathrm{R}=\mathrm{CH}_{2} \mathrm{CH}_{2} \mathrm{Ph}, 0.2 \mathrm{M}, 18 \mathrm{~h}, 80 \%$ (threo : erythro $=64: 36$ ) 


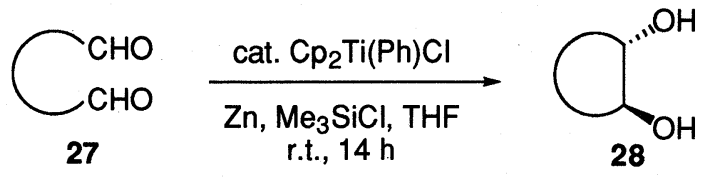

Table 3. Catalytic pinacol coupling of dials (27) by 22 / $\mathrm{Zn} / \mathrm{Me}_{3} \mathrm{SiCl}$.

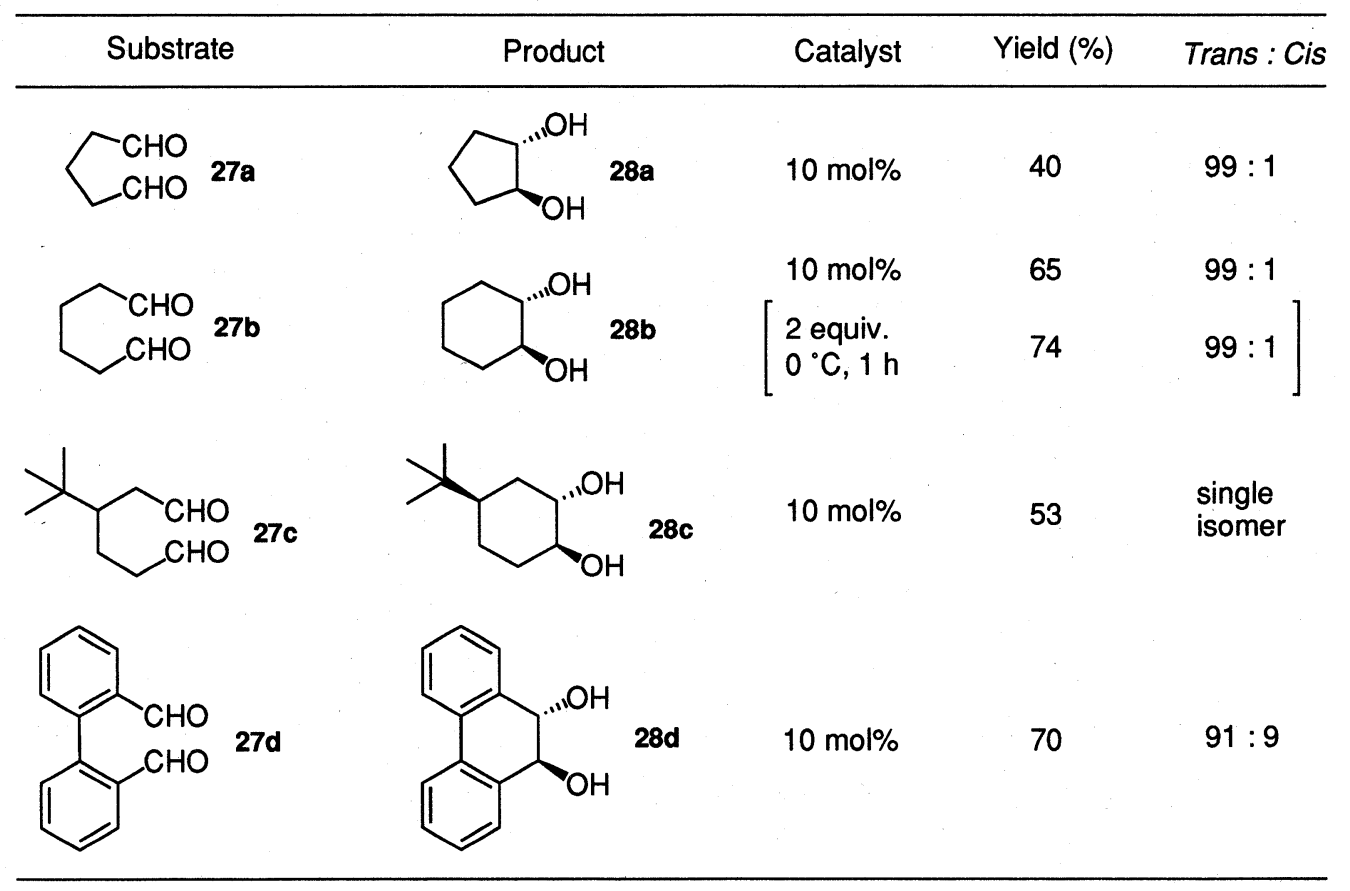

Acknowledgments.

Financial support from the Ministry of Education, Science, Culture, and Sports, Japanese Government (Grant-in-Aid 09238215, 09305059, 09750947, 10132222, 11119223), by Mitsubishi Chemical Coorporatiom, and TOSO Co. Ltd. are gratefully acknowledged.

\section{References and Notes}

(1) (a) Takacs, J. M. In Comprehensive Organometallic Chemistry II, Hegedus, L. S.; Abel, E. W.; Stone, F. G. A.; Wilkinson, G., Eds.; Pergamon: Oxford, 1995; Vol. 12, p 9. (b) Broene, R. D. In Comprehensive Organometallic Chemistry II, Hegedus, L. S., Ed.; Pergamon: Oxford, 1995; Vol. 12, p 323. (c) Ojima, I.; Tzamarioudaki, M.; Li, Z.; Donovan, R. J. Chem. Rev. 1996, 96, 635. (d) Chatani, N.; Murai, S. Synlett 1996, 414.

(2) Grotjahn, D. B., In Comprehensive Organometallic Chemistry II, Hegedus, L. S.; Abel, E. W.; Stone, F. G. A.; Wilkinson, G., Eds.; Pergamon: Oxford, 1995, Vol. 12, p 741.

(3) Yamamoto, Y.; Kitahara, H.; Ogawa, R.; Itoh, K. J. Org. Chem. 1998, 63, 9610. 
(4) Yamamoto, Y.; Kitahara, H.; Ogawa, R.; Kawaguchi, H.; Tatsumi, K.; Itoh, K. Submitted for publication.

(5) Yamamoto, T.; Kitahara, H.; Hattori, R.; Itoh, K. Organometallics 1998, 17, 1910.

(6) Pu, L.; Hasegawa, T.; Parkin, S.; Taube, H. J. Am. Chem. Soc. 1992, 114, 2712 and 7609: J. Am. Chem. Soc. 1993, 115, 2545.

(7) Yamamoto, Y.; Ohkoshi, N.; Kameda, M.; Itoh, K. J. Org. Chem. 1999, 64, 2178.

(8) [Ni] Radetich, B.; RajanBabu, T. V. J. Am. Chem. Soc. 1998, 120, 8007. [Pd] Widenhoefer, R. A.; DeCali, M. A. J. Am. Chem. Soc. 1998, 120, 3805. [Lanthanoids]: Molander, G. A.; Nicholas, P. J. J. Am. Chem. Soc. 1995 117, 4415. Molander, G. A.; Knigh, E. E. J. Org. Chem. 1998, 63, 7009. Onozawa,S.; Sakakura, T.; Tanaka, M. Tetrahedron Lett. $1994,35,8177$.

(9) (a) Matsuda, I.; Ogiso, A.; Sato, S.; Izumi, Y. J. Am. Chem. Soc. 1989, 111. (b) Matsuda, I.; Ogiso, A.; Sato, S. J. Am. Chem. Soc. 1990, 112, 6120. (c) Ojima, I.; Ingallina, P.; Donovan, R. J.; Clos, N. Organometallics 1991, 10, 38. (d) Matsuda, I.; Sakakibara, J.; Nagashima, H. Tetrahedron Lett. 1991, 32, 7431. (e) Matsuda, I.; Sakakibara, J.; Inoue, H.; Nagashima, H. Tetrahedron Lett. 1992, 33, 5799. (f) Doyle, M. P.; Shanklin, M. S. Organometallics, 1994. 13, 1081. (g) Matsuda, I.; Fukuta, Y.; Tsuchihashi, T.; Nagashima, H.; Itoh, K. Organometallics 1997, 16, 4327.

(10) Ojima, I.; Fracchiolla, D. A.; Donovan, R. J.; Banerji, P. J. Org. Chem. 1994, 59, 7594 . (b) Matsuda, I.; Ishibashi, H.; Ii, N. Tetrahedron Lett. 1995, 36, $241 . \quad$ (c) Ojima, I.; Fracchiolla, D. A.; Kass, D.; Zhu, J. Organometallics 1996,15, 5191. (d) Ojima, I.; Zhu, J.; Vidal, E. S.; Kass, D. F. J. Am. Chem. Soc. 1998, 120, 6690.

(11) Reviews: Shore, N. E. Org. React. 1991, 40, 1. Shore, N. E. In Comprehensive Organometallic Chemistry II, Hegedus, L. S.; Abel, E. W.; Stone, F. G. A.; Wilkinson, G., Eds.; Pergamon: Oxford, 1995, Vol. 12, p 73. Shore, N. E. In Comprehensive Organic Synthesis, Trost, B. M.; Fleming, I., Eds.; Pergamon: Oxford, 1991, Vol. 5, p 1037. Sugihara, T.; Yamaguchi, M.; Mishizawa, M. J. Org. Chem. Soc. Jpn. 1999, 57, 158.

(12) (a) Morimoto, T.; Chatani, N.; Fukumoto, Y.; Murai, S. J. Org. Chem. 1997, 62, 3762. Kondo, T.; Suzuki, N.; Okada, T.; Mitsudo, T. J. Am. Chem. Soc. 1997, 119, 6187. Koga, Y.; Kobayashi, T.; Narasaka, K. Chem. Lett. 1998, 249.

(13) Fukuta, Y.; Matsuda, I.; Itoh, K. Tetrahedron Lett. 1999, 40, 4703.

(14) Muraoka, T.; Matsuda, I.; Itoh, K. Tetrahedron Lett. 1998, 39, 7325.

(15) Matsuda, I.; Takeuchi, K.; Itoh, K. Tetrahedron Lett. 1999, 40, 2553.

(16) Suzuki, H.; Itoh, K.; Ishii, Y.; Simon, K.; Ibers, J. A. J. Am. Chem. Soc. 1976, 98, 8494. Brown, L. E.; Itoh, K.; Suzuki, H.; Hirai, K., Ibers, J. A. J. Am. Chem. Soc. 1978, 100, 8232.

(17) Yamamoto, Y.; Nagata, A.; Itoh, K. Tetrahedron Lett. 1999, 40, 5035.

(18) Yamamoto, Y.; Matsumi, D.; Itoh, K. Chem. Commun. 1998, 875.

(19) Yamamoto, Y.; Matsumi, D.; Hattori, R.; Itoh, K.J. Org. Chem. 1999, 64, 3224.

(20) For other methods of ketonitrile cyclization, see: (a) [Zn]: Corey, E. J.; Pyne, S. G. Tetrahedron Lett. 1983, 24, 2821. (b) [SmI $]$ : Molander, G. A.; Wolde, C. N. J. Org. Chem. 1998, 63, 9031. (c) [Electrochemical reduction]: Shono, T.; Kise, N.; Fujimoto, T.; Tominaga, N.; Morita, H. J. Org. Chem. 1992, 57, 7175.

(21) (a) Yamamoto, Y.; Hattori, R.; Itoh, K. Chem. Commun. 1999, 825. (b) Lipski, T. A.; Hilfiker, M. A.; Nelson, S. G. J. Org. Chem. 1997, 62, 4566. (c) Hirao, T.; Hatano, B.; Asahara, M.; Muguruma, Y.; Ogawa, A. Tetrahedron Lett. 1988, 39, 5247. (d) Reviews of pinacol coupling: Dushin, R. G. In Comprehensive Organometallic Chemistry II, Ed. Hegedus L. S.; Abel, E. W.; Stone, F. G. A.; Wilkinson, G., Eds.; Pergamon: Oxford, 1995, Vol. 12, p 1071. Robertson, G. M. In Comprehensive Organic Synthesis, Trost, B. M.; Fleming, I., Eds.; Pergamon: Oxford, 1991, Vol 3. p 563. Hirao, T. Synlett 1999, 175.

(Received June 23, 1999) 